\title{
Primary Afferent NMDA Receptors Increase Dorsal Horn Excitation and Mediate Opiate Tolerance in Neonatal Rats
}

\author{
Jinsong Zeng, ${ }^{1}$ Lisa M. Thomson, ${ }^{1}$ Sue A. Aicher, ${ }^{2}$ and Gregory W. Terman ${ }^{1}$ \\ ${ }^{1}$ Department of Anesthesiology and the Graduate Program in Neurobiology and Behavior, University of Washington School of Medicine, Seattle, \\ Washington 98195, and 2Neurological Sciences Institute, Oregon Health \& Science University, Beaverton, Oregon 97006
}

Repeated exposure to opiates produces analgesic tolerance, which limits their clinical usefulness. Whole-cell voltage-clamped lamina I cells in spinal slices from opiate-tolerant neonatal rats show an increase in miniature, spontaneous, and primary afferent-evoked EPSCs when compared with lamina I cells from opiate-naive rat spinal slices. This increased excitation can be blocked by the NMDA receptor (NMDAR) antagonist APV, apparently acting at NMDARs on primary afferents. Consistent with these results, electron microscopy demonstrates an increased incidence of NMDARs in substance P-containing spinal dorsal horn primary afferent terminals in opiatetolerant rats. Moreover, superfusion of spinal slices from opiate-tolerant rats with NMDA produces a reversible increase in miniature EPSC (mEPSC) frequency in contrast to a decrease in mEPSC frequency produced by NMDA in opiate-naive slices. Finally, NMDAR antagonists inhibit the expression of opiate tolerance both in inhibiting EPSCs in spinal slices and in inhibiting behavioral nociceptive responses to heat.

NMDAR antagonists have been reported in many studies to inhibit morphine analgesic tolerance. Our studies suggest that an increase in primary afferent NMDAR expression and activity mediates a hypersensitivity to noxious stimuli and causes the inhibition of opiate efficacy, which defines tolerance.

Key words: voltage clamp; electrophysiology; pain; sensitization; opponent process; in vitro

\section{Introduction}

For thousands of years opiates have been the gold standard for treatment of severe pain. Unfortunately, prolonged or repeated opiate exposure often produces a tolerance to their effects such that more and more drug is necessary to produce the same pain relief. The mechanisms mediating opiate tolerance are multifaceted, including both pharmacological and physiological adaptations (Hsu and Wong, 2000; Liu and Anand, 2001). For example, like other G-protein-coupled receptors, opiate receptors reconstituted in expression systems show a reduction in agonist effect with prolonged agonist exposure with phosphorylation by G-protein-coupled receptor kinases (GRKs) (Ferguson et al., 1996; Kovoor et al., 1997; Yu et al., 1997; Lowe et al., 2002). We recently have implicated GRKs in mediating tolerance to the behavioral and electrophysiological effects of the highly efficacious opiate fentanyl (Terman et al., 2004), but not to the same effects of another opiate, morphine (cf. Bohn et al., 2000). This points to a redundancy of mechanisms mediating opiate tolerance.

Indeed, numerous other mechanisms of opiate tolerance have been reported. Many of these can be described as compensatory

Received Dec. 22, 2005; revised Sept. 11, 2006; accepted 0ct. 4, 2006.

This work was supported by National Institutes of Health Grants DA14588 (G.T.) and DE12640 (S.A.). L.T. was supported by T32 DA07278, an institutional fellowship from the National Institute on Drug Abuse (NIDA). DAMGO and naloxone used in these studies were gifts from the NIDA drug supply system. We thank Marc B. Silverman and Clayton W. Winkler for their technical assistance with the anatomical studies.

Correspondence should be addressed to Dr. Gregory Terman, Department of Anesthesiology, P.0. Box 356540, University of Washington, Seattle, WA 98195-6540. E-mail: gwt@u.washington.edu.

DOI:10.1523/JNEUROSCI.2530-06.2006

Copyright $\odot 2006$ Society for Neuroscience ～0270-6474/06/2612033-10\$15.00/0 (or opponent) processes (Harrison et al., 1998; Hsu and Wong, 2000). For instance, evidence from a number of laboratories (Proudfit and Hammond, 1981; Woolf, 1981; Mao et al., 1995; Laulin et al., 1999; Vanderah et al., 2001) suggests that analgesic tolerance to $\mu$-opiate agonists is mediated predominantly not by changes in opiate receptor function but by the development of a decreased pain threshold with repeated opiate exposure, sometimes called opiate-induced hyperalgesia (Vanderah et al., 2001). Activity-dependent synaptic plasticity throughout the nervous system (Lopes da Silva et al., 1992; Dobkin, 1993; Hawkins et al., 1993), including hypersensitivity in pain-processing systems (Coderre et al., 1993) and, in particular, opiate-induced hyperalgesia (Manning et al., 1996), has been linked to NMDA-type glutamate receptor (NMDAR) activity. NMDAR antagonists have been reported to inhibit the development or expression of opiate tolerance in $>50$ studies. It is possible that the inhibition of opiate tolerance by NMDAR antagonists is attributable to the inhibition of opiate-induced hyperalgesia.

To test this hypothesis, we began by developing an in vivo model of opiate analgesic tolerance in the neonatal rat by using repeated injections of escalating doses of morphine (Zhu and Barr, 2003). After demonstrating opiate analgesic tolerance in a heat-induced paw withdrawal test, we began to compare electrophysiological responses in slices of the spinal cord taken from opiate-tolerant rats with those in slices from opiate-naive rats. Whole-cell voltage-clamped cells in lamina I of the dorsal horn of spinal slices from opiate-tolerant rats showed significantly less $\mu$-opiate-induced inhibition of evoked and spontaneous excita- 
tory responses than lamina I cells in opiate-naive slices (Eastman and Terman, 2001) (C. Eastman and G. W. Terman, unpublished observations). The current studies were prompted by our initial impressions that lamina I neurons from opiate-tolerant rats showed more spontaneous excitation than lamina I cells from opiate-naive rats.

\section{Materials and Methods}

Animals. Sprague Dawley time-mated dams were purchased (Taconic, Germantown, NY) and gave birth in our animal care facility. Veterinary care was provided by the Department of Comparative Medicine, fully accredited by the Association for Assessment and Accreditation of Laboratory Animal Care and licensed by the United States Department of Agriculture for rat care. Studies were performed when rat pups were 12-17 d of age. All studies were in accordance with the guidelines for animal research published by the International Association for the Study of Pain and the Society for Neuroscience and were in compliance with the regulations of the Institutional Animal Care and Use Committee (IACUC) at the University of Washington. All anatomy studies were performed at the Oregon Health \& Science University. Morphine tolerance induction was performed at the University of Washington, and the animals were shipped from Seattle, WA to Portland, OR for perfusion and processing as approved by the Oregon Health \& Science University IACUC.

Opiate tolerance protocol. Opiate analgesic tolerance was induced with six twice-daily (morning and evening) subcutaneous injections of morphine $(15,30$, and $45 \mathrm{mg} / \mathrm{kg}$ on days 1,2 , and 3, respectively). All experiments were conducted $16-40 \mathrm{~h}$ after completion of the injection regimen.

Nociceptive testing. Hindpaw withdrawal from heat was assessed by placing rat pups (14-15 d old) in a Plexiglas chamber with a movable heat source aimed from beneath the chamber at the subject's hindpaw. Light intensity was adjusted to yield baseline withdrawal latencies of 4-5 $\mathrm{s}$, with a $15 \mathrm{~s}$ upper limit of heat exposure imposed to avoid tissue damage. Baseline testing included five paw withdrawal trials (given at $1 \mathrm{~min}$ intervals), with the mean of the last three trials defining the baseline value. After the drug injections each animal was tested at $30 \mathrm{~min}$ intervals with three paw withdrawal trials (again at 1 min intervals), with the mean of the three trials defining the latency for that session. Pups were returned to their home cages between testing sessions.

Behavioral data analysis. ANOVA was used to compare the behavioral data sets statistically. Group by trial two-way ANOVAs, with one repeated measure, were performed for baseline and postdrug measurements. The Newman-Keuls test was used for appropriate post hoc comparisons of between-group differences at any one time point. An $\alpha$ value of $p<0.05$ was used to indicate significant differences.

Spinal slice preparation. Methods in preparing viable spinal slices were adapted from the methods of Berger and Takahashi (1990) as previously described (Terman et al., 2001). Briefly, a laminectomy was performed in young rats (12-17 d old) anesthetized with halothane. Animals then were decapitated, and the spinal cord was removed and bathed in an ice-cold dissecting buffer (previously bubbled with $95 \% \mathrm{O}_{2} / 5 \% \mathrm{CO}_{2}$ for at least $1 \mathrm{~h}$ ). The isolated spinal cord was placed in a small Petri dish, embedded in low-melting-point agar [2\%, w/v in modified artificial CSF (aCSF) containing the following (in $\mathrm{mm}$ ): $113 \mathrm{NaCl}, 3 \mathrm{KCl}, 1 \mathrm{NaH}_{2} \mathrm{PO}_{4}, 25$ $\mathrm{NaHCO}_{3}, 11$ glucose, $\left.2 \mathrm{CaCl}_{2}, 2 \mathrm{MgCl}_{2}\right]$, and cooled to $34^{\circ} \mathrm{C}$. A block of agar containing the lower lumbar cord (L4-L6) was cut out and glued to the cutting chamber of a vibratome with cyanoacrylate glue. The chamber was filled with ice-cold bubbled dissecting buffer [composed of the following (in mM): $113 \mathrm{NaCl}, 3 \mathrm{KCl}, 1 \mathrm{NaH}_{2} \mathrm{PO}_{4}, 25 \mathrm{NaHCO}_{3}, 11$ glucose, $10 \mathrm{MgCl}_{2}$ ], and $300-400 \mu \mathrm{m}$ transverse sections of the spinal cord were cut. Slices were transferred by a Pasteur pipette to a Plexiglas experimental chamber attached to a fixed stage Axioskop FS microscope equipped with a bandpass optical filter $(770 \pm 40 \mathrm{~nm})$ in the light path and an attached CCD camera and monitor. Additional slices, not currently being studied, were placed in a chamber containing bubbled room temperature aCSF.

Slices placed in the experimental chamber were held in place with a platinum wire harp and were perfused continuously with aCSF (1-2 $\mathrm{ml} / \mathrm{min})$. Bicuculline $(10 \mu \mathrm{M})$ and strychnine $(1 \mu \mathrm{M})$ were added to the aCSF in all experiments to ensure the specific study of EPSCs. Miniature EPSCs (mEPSCs) were evaluated by adding tetrodotoxin (TTX; $0.3 \mu \mathrm{M}$ ) to block action potentials.

A stimulating electrode (MCE-100, Rhodes Medical Instruments, Woodland Hills, CA) was aimed by using a $4 \times$ objective at the tract of Lissauer superficial to the dorsal horn at the most dorsolateral edge of the dorsolateral funiculus.

Electrophysiological recordings. The temperature of the bath in the recording chamber was heated to $34^{\circ} \mathrm{C}$ by an in-line heater (Warner Instruments, Grand Haven, MI) with feedback control. A glass recording electrode (4-6 M $\Omega$ ) filled with intracellular pipette solution [containing the following (in mM): $125 \mathrm{KMeSO}_{4}, 8 \mathrm{NaCl}, 10$ HEPES, $2 \mathrm{Mg}$-ATP, 0.3 Na-GTP, and 5 EGTA, pH 7.3, at $\sim 285$ mOsm] was advanced into the recording chamber by using direct vision and a micro-manipulator (Sutter Instrument, Novato, CA). Lamina I cells were targeted visually for whole-cell voltage-clamp recording. Maximum diameter of the cell body was measured by using Openlab software (Improvision, Lexington, MA). Once established, whole-cell voltage clamp was maintained at $-70 \mathrm{mV}$, using an Axopatch 200B amplifier (Molecular Devices, Union City, CA) and telegraphed software (Pulse, HEKA Electronics, Lambrecht, Germany) running on a Macintosh computer. Initial series resistance and capacitance as well as current/voltage curves were noted at the beginning of each experiment and at intervals throughout the study (series resistance and capacitance changes $>20 \%$ eliminated data from study analysis).

Electrophysiology drug application. $\quad\left[\mathrm{D}-\mathrm{Ala}^{2}, \mathrm{~N}-\mathrm{MePhe}^{4}, \mathrm{Gly}-\right.$ $\mathrm{ol}^{5}$ ] enkephalin (DAMGO) and naloxone used in these studies were gifts from the National Institute of Drug Abuse (NIDA) drug supply system. All other drugs were purchased (Sigma, St. Louis, MO). Drugs were applied by gravity-fed superfusion from a drug reservoir containing bubbled aCSF in which the drugs were dissolved. The combined volume of the recording chamber and tubing from the drug reservoir was $<2 \mathrm{ml}$ to minimize latencies of drug effects at a flow rate of $1-2 \mathrm{ml} / \mathrm{min}$.

Primary afferent stimulation. The tract of Lissauer was stimulated every $30 \mathrm{~s}$, and the pulse duration (usually $1-2 \mathrm{~ms}$ ) and current intensity (usually $50-100 \mu \mathrm{A}$ ) were adjusted to produce a reliably evoked EPSC distinguishable from the stimulus artifact. After stable (10-15 $\mathrm{min}$ ) stimulation-evoked EPSCs (baseline) were established, the drugs were applied and reversed by antagonist or by drug washout. In some studies evoked (eEPSCs) and spontaneous EPSCs (sEPSCs) were recorded concurrently in alternating intervals.

Electrophysiological data analysis. All electrophysiological data were digitized and collected via Pulse (HEKA Electronics) on a Macintoshbased computer. From Pulse the data were exported into a spreadsheet for additional data manipulation (Microsoft Excel, Redmond, WA), graphing (Synergy KaleidaGraph, Reading, PA), or statistics (StatSoft STATISTICA, Tulsa, OK). Analysis of spontaneous or miniature potentials was accomplished with MiniAnalysis (Synaptosoft, Decatur, GA). MiniAnalysis allows for a threshold-based event detection algorithm, enabling events to be analyzed by frequency and amplitude as well as to be grouped and plotted.

Stimulus-evoked EPSCs are analyzed both with respect to maximum initial amplitude (the first $\sim 20 \mathrm{~ms}$ ) and charge (area under the baseline holding current) of the response. Post-treatment data are normalized to baseline responses (post-treatment/baseline) to minimize cell-to-cell variance and facilitate between-subject ANOVA. Baseline is defined in the stimulation-evoked EPSC studies as the mean of five pretreatment responses. sEPSCs were recorded in 2 min epochs, and mEPSCs were recorded in 5 min epochs, with the last pretreatment epoch serving as baseline. As in the behavioral studies ANOVA and Newman-Keuls tests and an $\alpha$ value of 0.05 were used to analyze these electrophysiology experiments statistically. An exception to this was the use of the Kolmogorov-Smirnov test to compare EPSC amplitudes.

Data from multiple cells in the same slice or from multiple slices in the same animal were treated as independent samples. However, recordings were made from only one cell in any one slice either stimulated electrically or given any drug treatment (excluding the bicuculline and strych- 
nine treatments routinely given to all slices). $n$ in the figures and figure legends refers to the total number of cell recordings in which the experiment was completed while maintaining whole-cell voltage clamp with minimal change $(<20 \%)$ in resistance or capacitance measures.

Immunohistochemistry and electron microscopy. Spinal cord tissues were prepared for dual immunoperoxidase and immunogold detection of substance P (SP) and NMDAR1 with methods previously described (Aicher et al., 1997). In brief, rat pups were anesthetized deeply with a lethal dose of sodium pentobarbital (150 mg/kg, i.p.) and perfused transcardially with $5 \mathrm{ml}$ of heparinized saline $(1000 \mathrm{U} / \mathrm{ml})$, followed by $10 \mathrm{ml}$ of $3.8 \%$ acrolein in $2 \%$ paraformaldehyde, followed by $50 \mathrm{ml}$ of $2 \%$ paraformaldehyde. The lumbosacral spinal cord was removed, placed in the acrolein/paraformaldehyde solution for $20 \mathrm{~min}$, and then placed in $0.1 \mathrm{~m}$ phosphate buffer (PB), $\mathrm{pH}$ 7.4. The spinal cord was sectioned [40 $\mu \mathrm{m}$ thick coronally on a vibrating microtome (Vibratome model VT1000, Leica Microsystems, Nussloch, Germany)], and the sections were collected in $0.1 \mathrm{M}$ PB. Tissue sections were stored for $3 \mathrm{~d}$ in a cryoprotectant solution at $-20^{\circ} \mathrm{C}$ before processing. Tissue sections were incubated in (1) $1 \%$ sodium borohydride $(30 \mathrm{~min})$ to neutralize the aldehydes and (2) $0.5 \%$ bovine serum albumin (BSA) in $0.1 \mathrm{~m}$ Tris-saline (Tris, $\mathrm{pH}$ 7.6) to reduce nonspecific binding. Tissue sections then were placed in a mixture of monoclonal rat anti-SP antibody (1:1000; Accurate Chemicals, Westbury, NY) and rabbit anti-NMDAR1 antibody (1: 50; Chemicon, Temecula, CA) in $0.1 \%$ BSA for $36 \mathrm{~h}$ at $4^{\circ} \mathrm{C}$. After incubation in the primary antibody mixture the sections were incubated in biotinylated anti-rat IgG (1:400) for $30 \mathrm{~min}$. Then the biotinylated secondary antibody was visualized by incubation of the sections in avidinbiotin complex $(\mathrm{ABC})$ solution (Elite kit, Vector Laboratories, Burlingame, CA) for $30 \mathrm{~min}$, followed by a $6 \mathrm{~min}$ incubation in diaminobenzidine- $\mathrm{H}_{2} \mathrm{O}_{2}$ solution. To visualize NMDAR1, we incubated the sections in a secondary antibody conjugated to colloidal gold (1:50 goat anti-rabbit IgG; Amersham Biosciences, Arlington Heights, IL) for $2 \mathrm{~h}$ and glutaraldehyde for $10 \mathrm{~min}$; then the colloidal gold was enhanced by silver intensification (IntenSEM kit, Amersham Biosciences) for 7 min. Except for the primary antibody mixture, all incubations were at room temperature, and tissue was rinsed in Tris-saline after each incubation.

After immunocytochemical processing the tissue sections were rinsed in $0.1 \mathrm{M} \mathrm{PB}$, placed in $2 \%$ osmium tetroxide for $1 \mathrm{~h}$, rinsed in $0.1 \mathrm{M} \mathrm{PB}$, dehydrated through a graded series of ethanols to propylene oxide, and then put in propylene oxide EMbed (1:1; Electron Microscopy Sciences, Hatfield, PA) overnight. Next the sections were placed in EMbed for $2 \mathrm{~h}$, embedded between two pieces of Aclar, and placed in an oven for $48 \mathrm{~h}$ at $60^{\circ} \mathrm{C}$. Vibratome sections containing SP-labeled axon terminals in the dorsal horn of the spinal cord were embedded in Beem capsules. Ultrathin sections $(75 \mathrm{~nm})$ were collected from the surface of the tissue, placed on copper grids, and counterstained with uranyl acetate and Reynold's lead citrate. Ultrathin sections were examined with an FEI Tecnai 12 electron microscope, and images were captured with a digital camera (Advanced Microscopy Techniques, Danvers, MA).

Anatomy data analysis. Electron microscopic images were collected with an Advanced Microscopy Techniques $2.6 \times 2.6 \mathrm{k}$ digital camera and saved in tagged image file (TIFF) format. Contrast and sharpness for all images were adjusted in Adobe Photoshop (Mountain View, CA) and labeled in Adobe Illustrator.

The ultrastructural analysis was conducted on plastic-embedded sections from four animals ( $n=4$; two morphine and two control rats) with successful immunoperoxidase and immunogold labeling and excellent preservation of morphology. Ultrathin sections were selected from an area just below the surface of the tissue at the tissue/plastic interface, where the penetration of antibodies is optimal (Aicher et al., 1995, 1999). Regions were selected for analysis on the basis of their location immediately inside the dorsal surface of the spinal cord or immediately adjacent to the dorsal funiculus. For each animal the area examined was four to five grid squares $\left(12,100-15,125 \mu \mathrm{m}^{2}\right)$. All SP-containing axons and terminals were photographed and quantified to determine the localization of immunogold labeling for NMDAR1 both presynaptically and postsynaptically. The localization of silver-intensified colloidal gold particles was classified as either plasmalemmal (in direct contact with the
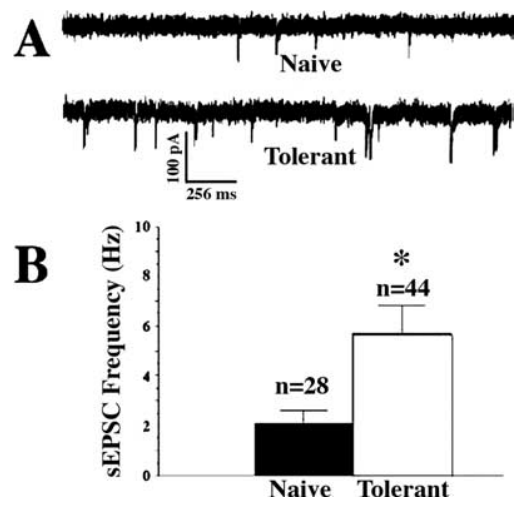

Figure 1. Increased excitatory postsynaptic currents in lamina I cells of spinal slices from morphine-tolerant neonatal rats. $\boldsymbol{A}$, Representative examples of whole-cell voltage-clamp recordings from lamina I cells in slices from an opiate-naive (Naive) and a morphine-treated (Tolerant) rat showing increased sEPSCs in the latter. $\boldsymbol{B}$, Significantly elevated mean sEPSC frequencies in cells from morphine-treated (Tolerant) rats as compared with cells from opiatenaive (Naive) rats ( $n$ refers to the number of cells, and frequencies for each cell represent an average frequency for at least $2 \mathrm{~min}$ ). Graphed values are the means \pm SEM; ${ }^{*} p<0.05$ signifies a statistically significant difference from cells in opiate-naive slices.

\section{Table 1. Representative cell characteristics $(n=15)$}

\begin{tabular}{lcc}
\hline & Naive & \multicolumn{1}{c}{ Tolerant } \\
\hline Cell body diameter $(\mu \mathrm{m})$ & $12.6 \pm 0.4$ & $12.3 \pm 0.4$ \\
Input resistance $(\mathrm{M} \Omega)$ & $665.1 \pm 38.9$ & $672.3 \pm 40.2$ \\
Capacitance $(\mathrm{pF})$ & $28.1 \pm 3.1$ & $29.3 \pm 3.8$ \\
Resting membrane potential $(\mathrm{mV})$ & $-63.7 \pm 7.2$ & $-64.5 \pm 3.9$ \\
Initial holding current at $-70 \mathrm{mV}(\mathrm{pA})$ & $-21.5 \pm 2.4$ & $-23.4 \pm 2.8$
\end{tabular}

Values are the means \pm SEM.

plasma membrane) or cytoplasmic. The criterion for positive immunogold labeling for NMDAR1 was the presence of at least two particles in profiles $0-1.0 \mu \mathrm{m}$, three particles for profiles $1.1-2.0 \mu \mathrm{m}$, and four particles for profiles $>2.1 \mu \mathrm{m}$ in diameter. Terminal and target size were measured as the maximum cross-sectional diameter of the structure. Associations between neuronal elements were identified and classified as either asymmetric or symmetric synapses or as appositions. The relative number of dual-labeled profiles was compared between treated and control animals by using a $\chi^{2}$ analysis. In addition, Student's $t$ tests were used to compare the total number of gold particles per unit area of duallabeled axon terminals as well as the ratio of membrane to cytoplasmic gold particles within each axon terminal between groups.

\section{Results}

Increased excitation in the dorsal horn of spinal slices from opiate-tolerant rats

In whole-cell voltage-clamp studies of visualized lamina I cells in the neonatal rat spinal cord we found a significantly increased frequency of sEPSCs in spinal cord slices from rats previously treated with opiates (opiate-tolerant) as compared with slices from opiate-naive rats (Fig. $1 A, B$ ). However, there was no significant difference between the two groups in sEPSC amplitudes (Kolmogorov-Smirnov test; data not shown). Moreover, there was no difference between any other measured anatomic or electrophysiological characteristics of the cells studied in the two groups of cells (Table 1). In the presence of $0.3 \mu \mathrm{M}$ TTX mEPSC mean frequencies also were elevated significantly $(p<0.05)$ in slices from opiate-tolerant rats $(0.61 \pm 0.05 \mathrm{~Hz} ; n=7$ cells $)$ when compared with opiate-naive slices $(0.29 \pm 0.02 \mathrm{~Hz} ; n=11$ cells $)$. Again there were no group differences in EPSC amplitudes, with mEPSC mean amplitude in cells $(n=11)$ from opiate-naive slices 
equaling $49.7 \pm 0.4 \mathrm{pA}$ as compared with $50.2 \pm 0.3 \mathrm{pA}$ in cells $(n=7)$ from slices from opiate-tolerant rats.

All of our spinal slice recordings described above included bicuculline $(10 \mu \mathrm{M})$ and strychnine $(1 \mu \mathrm{M})$ in the perfusion buffer to block inhibitory postsynaptic currents caused by $\mathrm{GABA}_{\mathrm{A}}$ and glycine receptors, respectively. Thus the increased sEPSC frequencies seen in opiate-tolerant slices were not attributable to a differential loss of inhibition (cf. Moore et al., 2002) but are, instead, attributable to increased excitation per se.

\section{Increased EPSC frequencies in morphine-tolerant slices are attributable to NMDA receptors}

A number of excitatory neurotransmitters in addition to glutamate have been reported to have activity in the spinal dorsal horn [including ATP (Ding et al., 2000), SP (Willcockson et al., 1984), and serotonin (Li and Zhuo, 1998)]. However, in our previous studies in opiate-naive slices (Terman et al., 2001) CNQX, a glutamate antagonist at kainate/AMPA-type receptors, virtually eliminated all sEPSCs and eEPSCs in lamina I recordings, pointing to glutamate as the primary excitatory transmitter in this region. In slices from morphine-tolerant rats CNQX again almost completely abolished all sEPSCs (Fig. 2A). Thus the increased sEPSCs recorded in tolerant slices are attributable to increased glutamate binding to CNQX-sensitive receptors. The increases in EPSC frequency, but not in amplitude, seen in tolerant slices argue that it is an increase in glutamate release that is responsible for the difference and thus an effect presynaptic to the cells from which we are recording.

The known importance of NMDA-type glutamate receptors in opiate tolerance described above prompted us to examine the effect of the NMDAR antagonist APV $(25 \mu \mathrm{M})$ in slices from morphine-tolerant rats. APV significantly decreased the sEPSC frequencies in tolerant slices to rates similar to those seen in opiate-naive slices (Fig. 2A) without having any effect on the sEPSC frequencies in slices from opiate-naive rats. Thus our data suggest that the increased glutamate release evident in lamina I of slices from opiate-tolerant rat pups is mediated by NMDA receptors. We hypothesized that these NMDARs likely are located presynaptic to the lamina I cells we studied. This hypothesis is based both on the magnesium blockade of most postsynaptic NMDARs seen at the $-70 \mathrm{mV}$ membrane potential at which we voltage clamp our cells during recordings and on the elimination of all EPSCs by CNQX (which does not block NMDARs). We went on to use the noncompetitive NMDAR blocker (+)-5-methyl10,11-dihydro- ${ }^{5} \mathrm{H}$-dibenzo [a,d]cyclohepten-5,10-imine maleate $(\mathrm{MK}-801)$ in our recording pipette solution to test this hypothesis. We (Thomson et al., 2006) and others (Arvanov et al., 2000; Garraway et al., 2003) have found that intracellular dialysis with MK-801 (1 mM) blocks postsynaptic NMDA-induced (but not CNQX-sensitive) currents in opiate-naive cells. Intracellular MK-801 does not occlude the ability of bath-applied APV to eliminate the increased frequencies of mEPSCs recorded in lamina I cells from opiate-tolerant rats, however (Fig. 2 B). Together, these data point to a presynaptic site of NMDARs involved in increasing the probability of glutamate release in the morphinetolerant rat's spinal dorsal horn.

We next examined whether the presynaptic NMDARmediated increases in glutamate release in tolerant rats might be attributable to changes at primary afferent nerve terminals. We have found previously that electrical stimulation of the tract of Lissauer (a region of white matter capping the spinal dorsal horn that contains fine primary afferent fibers thought to be involved in pain) (Coggeshall et al., 1981) can yield monosynaptic re-

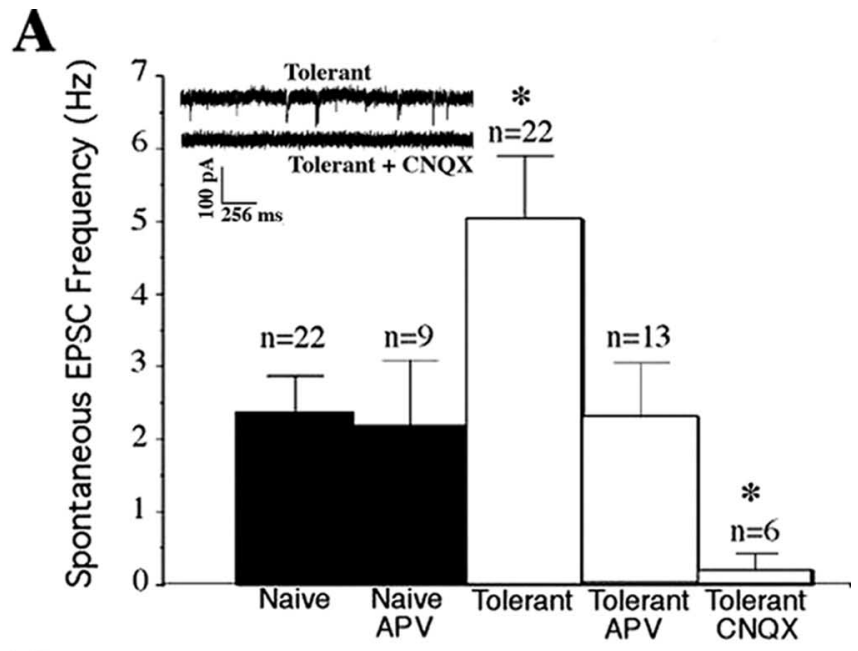

B

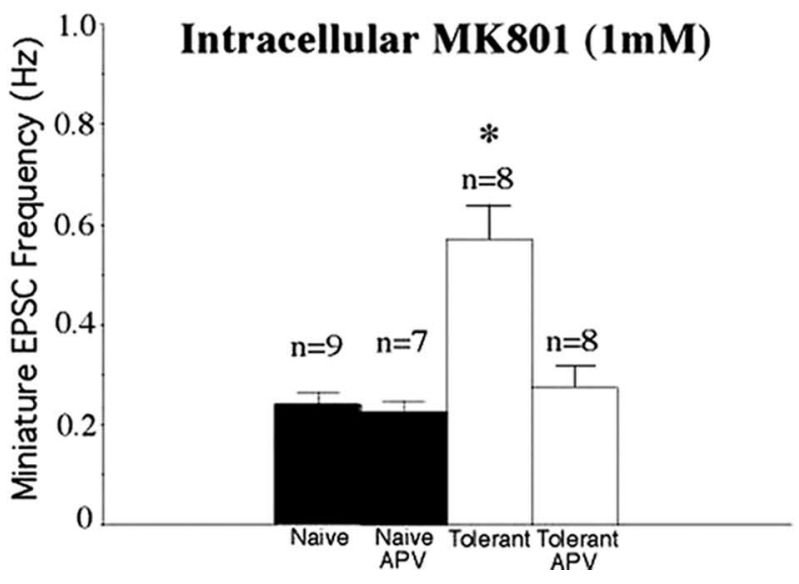

Figure 2. Increased EPSC frequencies in slices from morphine-tolerant rats are attributable to NMDA receptor-mediated currents. $\boldsymbol{A}$, The NMDA receptor antagonist APV $(25 \mu \mathrm{m})$ inhibits the frequency of $s E P S C S$ recorded in slices from morphine-treated rats (Tolerant), but not opiate-naive rats (Naive), such that after APV there is no longer a significant difference in sEPSC frequency between the two groups of slices. The kainate/AMPA glutamate receptor antagonist CNQX (10 $\mu \mathrm{m})$ virtually eliminated all sEPSCs in lamina I cells from morphine-treated rats, mirroring our previous data in opiate-naive slices and demonstrating the absence of postsynaptic NMDAR-mediated currents in our recordings. $\boldsymbol{B}$, Elevated mEPSC frequencies in slice recordings of neurons $(n)$ from morphine-treated rats (Tolerant) also were diminished by APV to levels of mEPSC frequencies observed in opiate-naive slices (Naive) by APV, even when the NMDA antagonist MK-801 was added to the intracellular pipette solution to block postsynaptic NMDA receptors. Data in both $A$ and $B$ represent repeated measure experiments in which APV or CNQX was added to the perfusate for $10 \mathrm{~min}$. Statistical analysis was performed by using either between-group or repeated measures ANOVA as appropriate, although predrug data (Naive or Tolerant) were collapsed across APV, CNQX, or no drug treatments for presentation purposes. Graphed values are the means $\pm \mathrm{SEM} ;{ }^{*} p<0.05$ signifies a significant difference from opiatenaive slices.

sponses in lamina I neurons (Li et al., 1999; Terman et al., 2001). We returned to this model, using tract of Lissauer stimulation, to evaluate differences between lamina I cells from morphinetolerant and morphine-naive slices in their responses to primary afferent stimulation. Just as in our sEPSC studies, there was a significant reversible inhibition by APV of eEPSCs in lamina I cells from morphine-tolerant rats (Fig. $3 A$ ), but not in cells from morphine-naive rats (Fig. $3 B$ ). This inhibition was seen both in the amplitude of the initial response to stimulation (Amplitude) and in the area under the curve (Charge) of the entire eEPSC. The inhibitory effect of APV on the amplitude of the initial eEPSC in tolerant slices suggests that at least a portion of the NMDAR- 


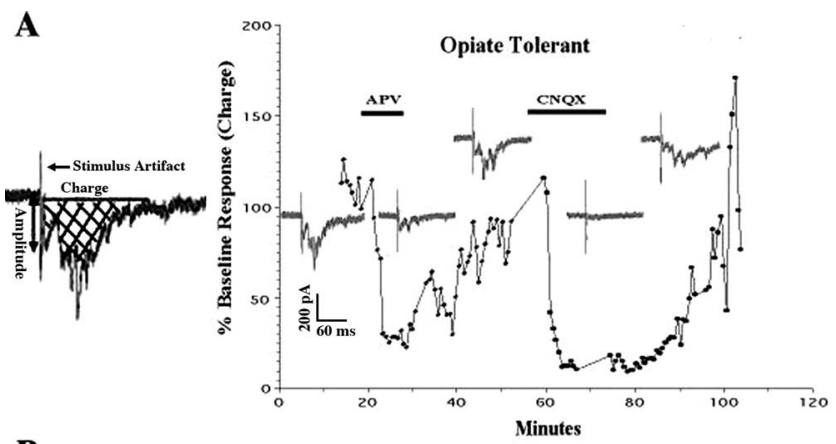

B
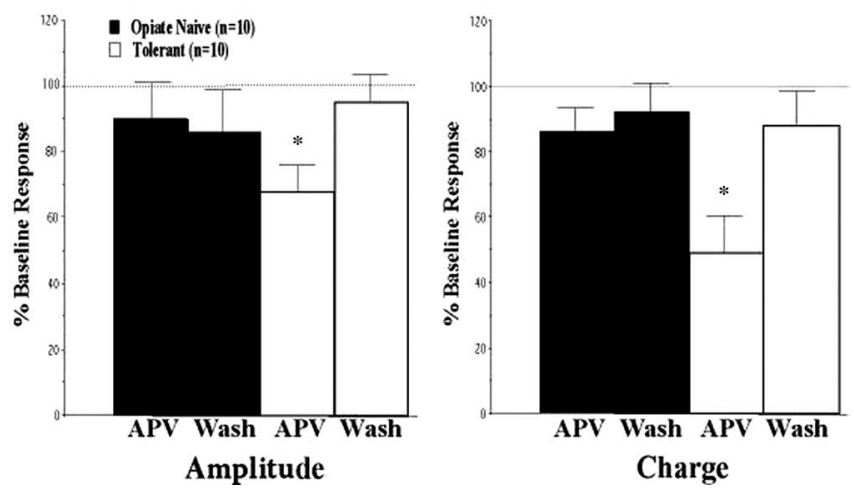

Figure 3. NMDA receptors potentiate tract of Lissauer eEPSCs in morphine-tolerant slices. $\boldsymbol{A}$, Representative experiment using a lamina I cell from a morphine-treated (0piate Tolerant) rat. Traces recorded at each phase of the study are included as insets, as well as the percentage of change from the immediate pre-APV (baseline) response area under the curve (Charge; see schematic). Infusion of APV ( $25 \mu \mathrm{m}$; horizontal bar) inhibited both maximal initial amplitude (Amplitude; see schematic) and the charge of the tract of Lissauer stimulation-evoked EPSCS (eEPSCs). This inhibition was reversed by stopping the APV (washing out the APV). Perfusion of CNQX (10 $\mu \mathrm{m}$; second horizontal bar) virtually eliminated all eEPSCs in slices from both opiatenaive (data not shown) and morphine-treated rats (as demonstrated). $\boldsymbol{B}$, Group data demonstrating inhibition of eEPSC amplitude and charge by APV in slices from morphine-treated rats (Tolerant) and significant reversal by 20 min of APV washout (Wash). $n$ refers to the number of cells from which adequate recordings were obtained. Graphed values are the means \pm SEM; ${ }^{*} p<0.05$ signifies a significant difference from APV washout.

mediated presynaptic effects is attributable to NMDARs on primary afferent terminals.

\section{Increased number of dorsal horn primary afferents containing NMDARs in morphine-tolerant rats}

Our electrophysiological studies point to an increase in presynaptic NMDA receptor activity in morphine-tolerant rats. We sought to confirm an increase in the number of these receptors via anatomical analyses. Presumed primary afferent terminals were identified by using an antibody to SP. An antibody specific for the R1 subunit of the NMDA receptor also was used to identify this type of glutamate receptor. Both SP and NMDAR1 were detected immunocytochemically (Aicher et al., 1997). Regions of the spinal dorsal horn were examined by electron microscopy in morphine-treated and opiate-naive control animals to determine whether any change in primary afferent terminal NMDARs could be verified.

The distribution of SP and NMDAR1 was examined in the spinal dorsal horn of morphine-treated and saline-treated control rats. A similar area of tissue at the tissue/plastic interface was examined in each animal, and the number and type of profiles were compared between control and morphine-treated rats. All profiles containing SP were photographed, and the distribution of NMDAR1 within these profiles was assessed. Consistent with our findings in adult animals (Aicher et al., 1997), SP was found in axons and axon terminals in the outer laminas of the neonatal rat spinal cord (Fig. 4). SP-containing terminals often formed asymmetric (presumed excitatory) synapses (Fig. 4A). Occasionally, SP and NMDAR1 were detected within the same unmyelinated axon (Fig. 4C). NMDAR1 also was found within SP axon terminals, where often it was associated with small clear vesicles (Fig. $4 D$ ). The prevalence of NMDAR1 within dorsal horn SP axon terminals was compared between opiate-treated and opiate-naive groups. We found that the frequency of NMDAR1 detection within SP-containing primary afferents was significantly higher in morphine-treated rats than in control rats (57 vs $35 \%$, respectively) (Table 2). Thus more of the SP axon terminals in morphine-treated rats had NMDAR1 as compared with control rats. This does not mean that there are more receptors per axon, however, because axon terminals that contained both SP and NMDAR1 demonstrated no group differences in the number of NMDARs (gold particles) per terminal (Table 2). Moreover, morphine treatment did not appear to change the ratio of NMDARs accessible to NMDAR agonists or antagonists on the cell membrane, because there was no difference in the cytoplasm/ membrane gold particle ratio between treatment groups for axon terminals containing both SP and NMDAR1 (Table 2). Thus our data demonstrate an increased synthesis and/or trafficking of NMDAR1 into SP terminals of morphine-treated rats as compared with controls and suggest that SP axon terminals that previously did not contain NMDARs now expressed them as a consequence of opiate exposure.

The difference in the frequency of NMDARs in SP-containing primary afferents in morphine-treated and control rats appeared to be a preferentially presynaptic effect. Some SP-labeled terminals contacted targets that were clearly dendritic. In both morphine and saline treatment groups $16 \%$ of these dendritic targets contained NMDAR1 immunogold labeling. Therefore, there was no difference between treatment groups with regard to the distribution of NMDAR1 in the dendritic targets of SP axon terminals. These findings suggest that morphine treatment associated with morphine analgesic tolerance causes an increased synthesis (or decreased degradation) of NMDA receptors in primary afferents and/or that there is an increase in trafficking of these receptors to primary afferent central terminals.

\section{Functional changes in presynaptic NMDARs in morphine-tolerant rats}

The increased number of primary afferent NMDARs evident in morphine-treated rats gives an anatomical basis for the increased NMDAR activity evident in our electrophysiology studies. Whether these new presynaptic NMDARs in morphine-treated rats function identically to the less abundant presynaptic NMDARs in opiate-naive rats cannot be determined from the anatomy.

Despite the extensive literature on the role of NMDA receptors in CNS neurotransmission, much less is known about the function of presynaptic NMDARs than postsynaptic NMDARs. This is likely attributable to the difficulty in studying small synaptic terminals directly as compared with voltage-clamp studies of postsynaptic cell bodies and their attached dendritic trees. Nevertheless, expanding numbers of studies have demonstrated a role for presynaptic NMDARs in modulating neurotransmission (Pittaluga and Raiteri, 1990; Liu et al., 1997; Lao et al., 2003; Bardoni et al., 2004; Huang and Bordey, 2004; Suarez et al., 2005; Yang et al., 2006) and synaptic plasticity (Duguid and Smart, 2004; Tzingounis and Nicoll, 2004; Garcia-Junco-Clemente et al., 
2005; Samson and Pare, 2005; Lien et al., 2006; Duguid and Sjostrom, 2006) throughout the brain and spinal cord. In general, presynaptic NMDARs have been implicated in increases in neurotransmitter release, although sometimes the neurotransmitters themselves are inhibitory (Duguid and Smart, 2004). An important exception to this generalization is a recent report by Bardoni et al. (2004) of an inhibition of spontaneous and primary afferent stimulation-evoked glutamate release in the spinal cord slice by direct application of NMDA. This finding in opiatenaive slices clearly differs from our data supporting a presynaptic NMDARmediated increase in glutamate release in slices from opiate-tolerant rats. We directly investigated this dichotomy by perfusing NMDA $(50 \mu \mathrm{M})$ onto spinal slices from opiate-tolerant and opiate-naive animals and observing the effects on lamina I mEPSC frequencies, with MK-801 in the recording pipette to block postsynaptic NMDA responses in the recorded cell. Like Bardoni et al. (2004), we observed a significant inhibition in EPSC frequency with NMDA administration in opiate-naive slices (Fig. $5 A, B$ ). This inhibition was reversed significantly $10 \mathrm{~min}$ after the NMDA had been removed from the perfusate (Fig. $5 A, B$, Wash). In contrast, in slices from opiate-tolerant rats the NMDA superfusion produced a significant revers-
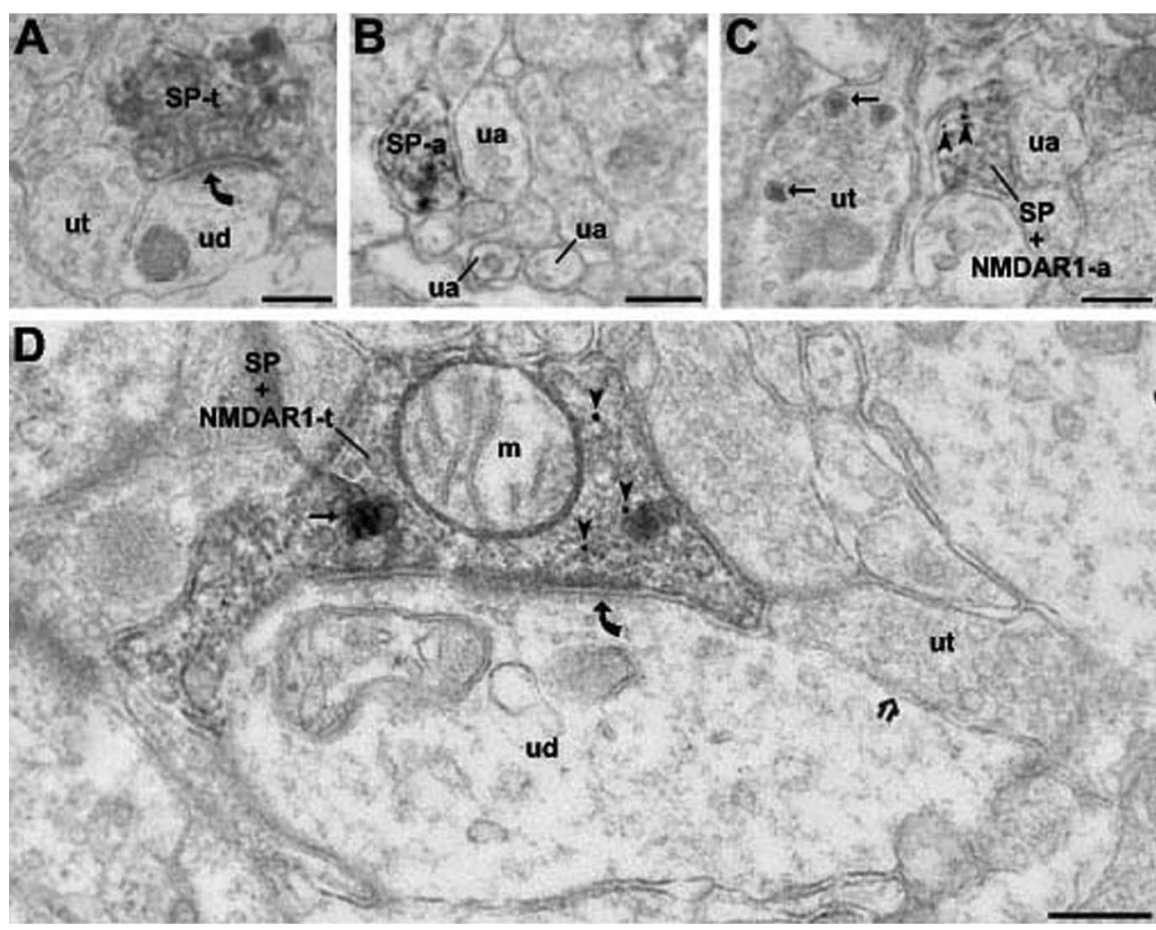

Figure 4. SP and NMDAR1 are colocalized at presynaptic sites in the spinal dorsal horn. $\boldsymbol{A}$, An immunoperoxidase SP-labeled terminal (SP-t) makes an asymmetric synapse (curved arrow) onto an unlabeled dendrite (ud). An unlabeled terminal is also in view (ut). $\boldsymbol{B}$, An SP-labeled unmyelinated axon (SP-a) in the outer laminas of the lumbar dorsal horn is seen in a bundle of small unmyelinated axons (ua). C, SP immunoperoxidase and NMDAR1 immunogold (arrowheads) labeling in an unmyelinated axon (SP + NMDAR1-a) are contrasted by an unlabeled unmyelinated axon (ua). Dense core vesicles (arrows) are seen in a nearby unlabeled terminal (ut). D, Immunoperoxidase labeling for SP and immunogold labeling for NMDAR1 (arrowheads) are colocalized in an axon terminal (SP + NMDAR1-t) that contained a dense core vesicle (arrow) and made an asymmetric synapse (curved arrow) onto an unlabeled dendrite (ud), which also received a direct apposition from an unlabeled terminal (open arrow; ut). $m$, Mitochondria. Scale bars, $0.25 \mu \mathrm{m}$.

ible increase in mEPSC frequency (Fig. 5).

After removal of the NMDA the mEPSC frequencies in opiatetolerant and opiate-naive slices were both below baseline levels, perhaps because of an unusually large nonspecific decrease in mEPSC frequencies with time ("rundown") in both groups (compare with the minimal rundown in Fig. $2 B$ ) and/or to a long-term effect of NMDA exposure. In either event the presynaptic NMDARs in the dorsal horn of opiate-treated animals differ from NMDARs in opiate-naive slices in their modulation of glutamate release and, thus, differ not only with regard to their number but also in their physiology. Both of these differences may contribute to the increased NMDAR-mediated excitation that is evident in spinal slices from opiate-tolerant neonatal rats.

\section{NMDA receptors contribute to opiate tolerance expression in vitro and in vivo}

We returned to our in vitro model of opiate tolerance to study further the possible functional implications of presynaptic NMDARs. We replicated our previous findings (Terman et al., 2001) that tract of Lissauer electrical stimulation-evoked EPSC amplitudes in lamina I cells from opiate-naive slices were inhibited by the $\mu$-agonist DAMGO $(1 \mu \mathrm{M})$ and that this inhibition was reversed by the opiate antagonist naloxone (1 $\mu \mathrm{M})$ (Fig. $6 A)$. Moreover, as in our previous studies (Eastman and Terman, 2001) (Eastman and Terman, unpublished observations) eEPSCs in lamina I cells from morphine-tolerant rat pups did not show naloxone-reversible inhibition of eEPSC amplitudes (Fig. 6A). In the presence of APV, however, significant DAMGO-induced inhibition was observed for both eEPSC amplitude and charge in
Table 2. Substance P immunoperoxidase-containing terminals (SP-t)

\begin{tabular}{llc}
\hline & Naive & Tolerant \\
\hline $\begin{array}{l}\text { Percentage containing NMDAR1 } \\
\quad \text { (immunogold labeling) }\end{array}$ & $35 \%(n=60$ SP-t) & $57 \% *(n=53$ SP-t) \\
Number of gold particles/terminal $^{\dagger \dagger}$ & $3.7 \pm 0.6$ & $4.2 \pm 0.6$ \\
Ratio of membrane gold/total gold $^{\text {t+ }}$ & $0.17 \pm 0.04$ & $0.15 \pm 0.04$ \\
\hline
\end{tabular}

Values are the means \pm SEM.

${ }^{*} p<0.05 \chi^{2}$

${ }^{\dagger+}$ Not significant; Mann-Whitney rank sum test.

slices from morphine-tolerant rats (Fig. 6B). Thus the expression of opiate tolerance appeared to be inhibited by NMDAR antagonism. This inhibition of opiate tolerance expression by NMDAR antagonists was unexpected. Most previous studies demonstrating NMDA antagonist blockade of opiate tolerance reported a prevention rather than a reversal of tolerance and, thus, an inhibition of tolerance induction, but not necessarily of tolerance expression (Trujillo and Akil, 1991, 1994; Mao et al., 1992).

We therefore decided to return to the in vivo preparation to examine the effects of NMDAR antagonists in inhibiting opiate tolerance expression in our 2- to 3-week-old rat pups. Although NMDAR antagonists have been reported to block tolerance induction in rats of this age (Zhu and Barr, 2003), the effects of NMDAR antagonists on tolerance expression in these animals have not been reported previously. Using the hindpaw withdrawal response to noxious heat, we found that, as in the past (Eastman and Terman, unpublished observations), our regimen of escalating doses of morphine indeed did induce opiate analge- 


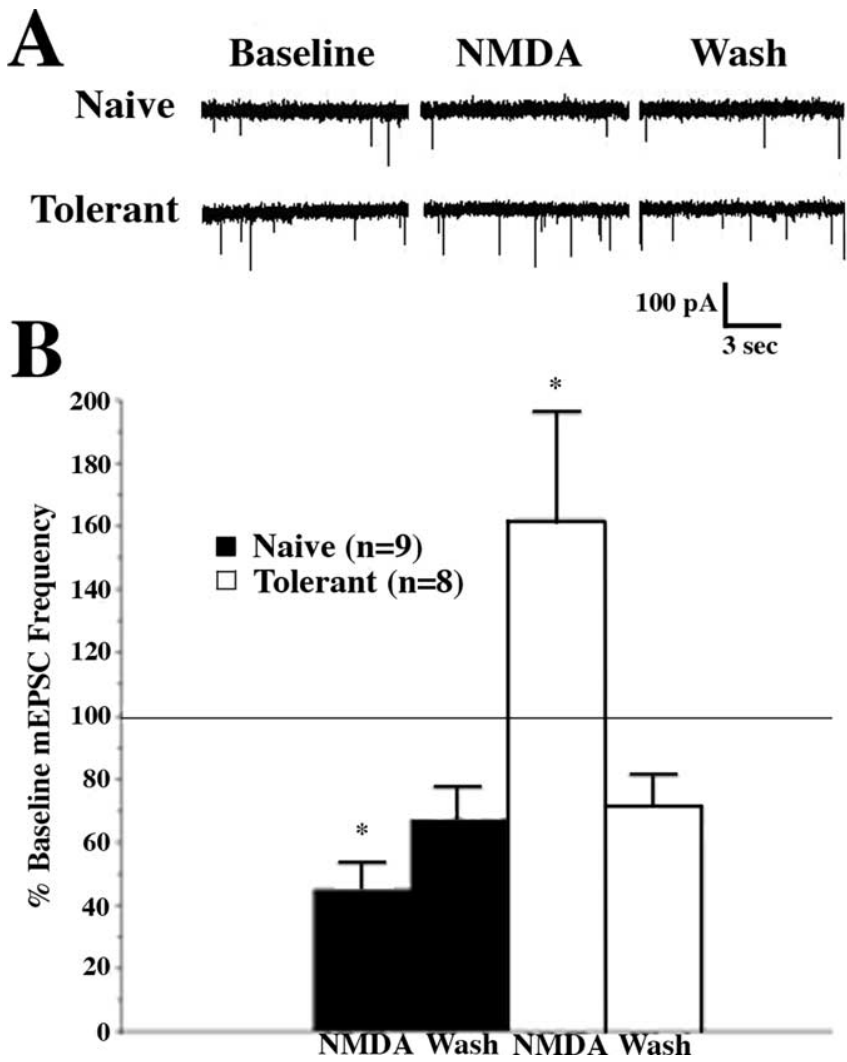

Figure 5. NMDA-induced potentiation of $m E P S C$ frequency in slices from morphine-tolerant rats. $A$, Representative examples of whole-cell voltage-clamp recordings from lamina I cells in slices from an opiate-naive (Opiate Naive) and a morphine-treated (Tolerant) rat in the presence of TTX $(0.3 \mu \mathrm{M})$ and with MK-801 $(1 \mathrm{~mm})$ in the recording electrode. NMDA $(50 \mu \mathrm{M})$ produces an inhibition of $\mathrm{mEPSC}$ frequency (from baseline frequency) in lamina I cells from spinal slices of opiate-naive neonatal rats that is reversed partially by removing NMDA from the bath (Wash) for $10 \mathrm{~min}$. In contrast, in lamina I cells from slices obtained from morphine-treated rats NMDA produces an increase in $m E P S$ ( frequency that is reversed completely by washing out NMDA. $\boldsymbol{B}$, Group data demonstrating a significant reversible (by Wash) reduction of mEPSC frequencies from baseline frequencies by NMDA application in slices from opiate-naive rats. $n$ refers to the number of cells from which adequate recordings were obtained. In contrast, there was a significant reversible increase in $\mathrm{mEPSC}$ frequencies from baseline by NMDA in slices from opiate-tolerant rats. Data consist of $\mathrm{mEPSC}$ frequencies averaged over a $5 \mathrm{~min}$ recording period, graphed as the percentage of pre-NMDA values (\% Baseline), and graphed as the means \pm SEM of these percentages. ${ }^{*} p<0.05$ signifies a significant difference in $\mathrm{mEPSC}$ frequencies from frequencies after 10 min of NMDA washout.

sic tolerance (Fig. 7). On the other hand, we found that $30 \mathrm{~min}$ of pretreatment with MK-801 blocked the expression of morphine analgesic tolerance in our rat pups $60 \mathrm{~min}$ after morphine (90 min after MK-801). Importantly, MK-801 did not affect premorphine or acute morphine hindpaw responses significantly (Fig. 7), demonstrating that this effect was not attributable to disruption of nociceptive responses or potentiation of morphine analgesia but was, instead, specific to analgesic tolerance.

We again were surprised by the inhibition of morphine tolerance expression produced by NMDAR antagonists in light of some previous negative reports in this regard (Trujillo and Akil, 1994). Perhaps our disparate results are attributable to differences between opiate tolerance in adult rodents (in which almost all of the NMDAR and opiate tolerance studies have been done) and the neonatal rats studied here. On the other hand, a review of the literature shows that even in adult animals only a small percentage of original studies reported experiments with NMDAR antagonists on tolerance expression $(\sim 10$ of 52 studies re-
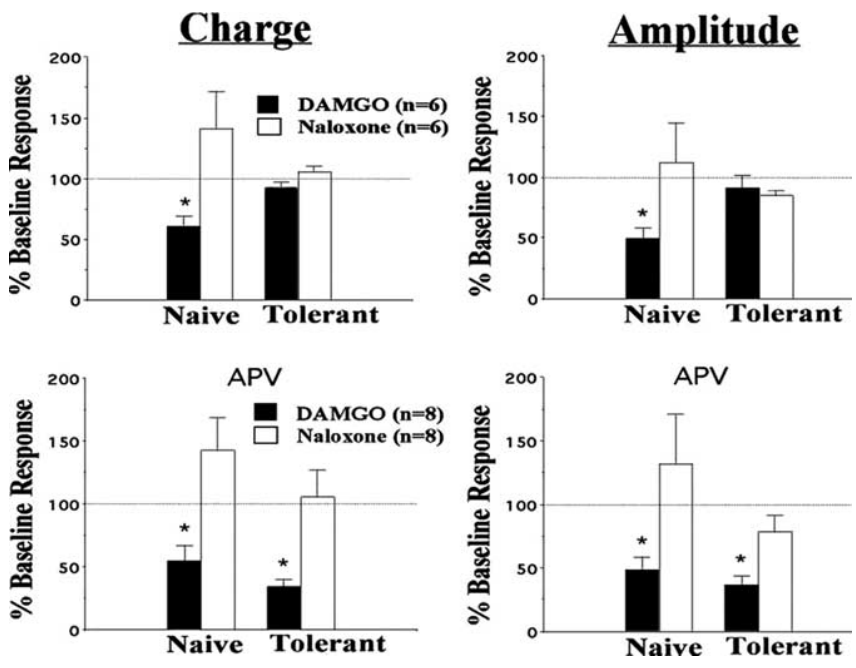

Figure 6. Inhibition of opiate tolerance expression by the NMDA receptor antagonist APV in vitro. At 10 min after perfusion with the $\mu$-opiate DAMGO $(1 \mu \mathrm{M})$, tract of Lissauer stimulationevoked EPSCs (eEPSCs) were inhibited with regard to both total Charge (left two panels; see Fig. 3 schematic for example of charge) and initial maximum amplitude (right two panels; see Fig. 3 schematic for example of amplitude) in lamina I cells from opiate-naive rats. This inhibition took place with APV ( $25 \mu \mathrm{m}$; bottom two panels) and without APV ( $25 \mu \mathrm{m}$; top two panels); all inhibition was reversed significantly by naloxone $(1 \mu \mathrm{M})$. Unlike eEPSCs in opiate-naive animals, DAMGO had no naloxone-reversible inhibition of response charge or amplitude in slices from morphine-tolerant rat pups in the absence of APV. In the presence of APV, however, naloxone-reversible inhibition was still significant, even in slices from morphine-tolerant pups. $n$ equals the number of cells from which adequate recordings were obtained. Graphed values are the means $\pm S E M ;{ }^{*} p<0.05$ signifies a significant difference from naloxone.
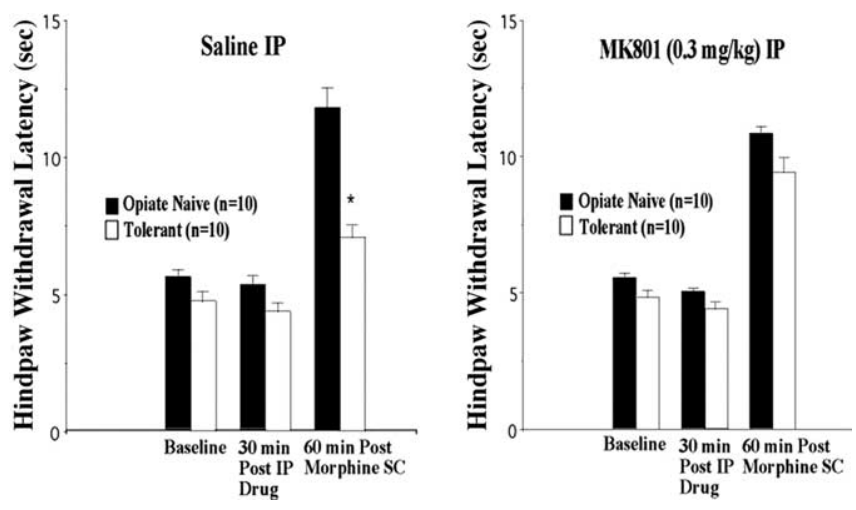

Figure 7. Inhibition of opiate analgesic tolerance expression by the NMDA receptor antagonist MK-801. Rat pups given $3 \mathrm{~d}$ of escalating dose morphine treatment (Tolerant) showed significantly less analgesia (inhibition of hindpaw withdrawal to heat) than saline-treated (0piate Naive) littermates 60 min after subcutaneous (SC) morphine when pretreated 30 min before morphine with saline, but not with the NMDA receptor antagonist MK-801, intraperitoneally (IP). Intraperitoneal MK-801 itself did not cause analgesia or potentiate morphine analgesia in the opiate-naive group. Graphed values are the means \pm SEM; ${ }^{*} p<0.05$ signifies a significant difference from opiate-naive rats.

viewed); of those, more than one-half have reported significant effects in inhibiting opiate analgesic tolerance expression with at least some doses of NMDAR antagonists (Tiseo and Inturrisi, 1993; Elliott et al., 1994; Shimoyama et al., 1996; McNally and Westbrook, 1998; Allen and Dykstra, 1999; Belozertseva et al., 2000; Popik et al., 2000). Some of these studies have been criticized because of motor (Carlezon et al., 2000) or sensory (Kozela and Popik, 2002) side effects produced by NMDAR antagonists including, in some studies, analgesia (Redwine and Trujillo, 2003) and morphine analgesia potentiation (Hoffmann and 
Wiesenfeld-Hallin, 1996). Nonetheless, although these confounds do complicate interpretation of opiate tolerance expression studies using NMDAR antagonists, they do not, in and of themselves, negate the possibility that NMDAR antagonists without such side effects, acting at the same receptor, might inhibit opiate tolerance expression. Indeed, our studies demonstrate that NMDARs are important in mediating morphine tolerance expression in the absence of sensory and/or motor side effects in vivo and that these effects correlate with a blockade of opiate tolerance by NMDAR antagonism in vitro for which behavioral side effects are not an issue.

\section{Discussion}

Neonatal rat pups exposed to previous repeated morphine injections show an increase in sEPSCs in lamina I of the spinal dorsal horn. Most of this increased excitation appears to be attributable to an increase in NMDA receptor activity, at least a portion of which appears to be at primary afferent terminals, presynaptic to the lamina I cells from which we recorded. Consistent with these electrophysiology results, electron microscopy data demonstrate an increased incidence of NMDARs in SP-containing spinal dorsal horn primary afferent terminals in opiate-tolerant neonatal rats. Moreover, superfusion of spinal slices from opiate-tolerant rats with NMDA produces a reversible increase in mEPSC frequency in contrast to the decrease in mEPSC frequency produced by NMDA in opiate-naive slices. Finally, this increased NMDARmediated excitation in opiate-exposed rats appears to be important in mediating opiate tolerance. NMDAR antagonists inhibit the expression of opiate tolerance both in our spinal slices and in behavioral nociceptive responses to heat.

Much like our studies in spinal dorsal horn, an increase in excitatory activity after repeated opiate administration also has been reported in whole-cell voltage-clamp studies of other regions of the neuraxis. Bie and Pan (2005) recently found an increase in glutamate release in brainstem slices of nucleus raphe magnus from opiate-tolerant rats. They proposed that this increased excitation is important in mediating opiate tolerance by increasing the activity of cells in the raphe magnus, which are known to be involved in descending nociceptive facilitation (Vanderah et al., 2001) but are normally under $\mu$-receptor inhibitory control (Pan, 2003). Bie and Pan report that the increased glutamate release is mediated by protein kinase $\mathrm{A}$ and protein kinase $\mathrm{C}$ activity; the role of NMDARs in their observations was not reported.

A role for NMDA receptors in contributing to morphine tolerance via NMDAR-mediated nociceptive sensitization has been hypothesized for at least a decade (Mao et al., 1995). Although other spinal and supraspinal opponent processes also have been shown to modulate opiate tolerance (Hsu and Wong, 2000), spinal NMDARs have been implicated most often in such mechanisms (Gutstein and Trujillo, 1993; Manning et al., 1996). Our studies suggest a cellular basis for the role of NMDARs in subserving opiate tolerance. The increase in NMDAR-mediated excitation in the superficial dorsal horn of the spinal cord certainly could contribute to a nociceptive sensitization that, in turn, produces a decrease in the antinociceptive efficacy of a given dose of opiate. How the role of NMDARs in opiate tolerance induction differs from their role in opiate tolerance expression requires more study and, perhaps, more pharmacological tools with an improved therapeutic window in vivo (Loftis and Janowsky, 2003; Petrenko et al., 2003). Particularly novel in our results is the demonstration that presynaptic rather than postsynaptic NMDARs are involved dynamically in regulating the increased excitation in spinal dorsal horn associated with opiate tolerance. Presynaptic NMDARs increasingly have been implicated in modulating CNS neurotransmission and synaptic plasticity (Duguid and Sjostrom, 2006), including increasing (Duguid and Smart, 2004; Yang et al., 2006) and decreasing (Bardoni et al., 2004) neurotransmitter release. Our findings that high doses of NMDA inhibit mEPSC frequency in superficial spinal laminas replicate the findings of Bardoni et al. (2004). Admittedly, this response to high doses of selective agonist does not speak directly to the physiological role of presynaptic NMDA receptors when exposed to endogenous levels of glutamate. Indeed, we recently have observed (Thomson et al., 2006) that increases in endogenous agonist by glutamate transporter inhibition produce an APVsensitive increase in mEPSC frequency in opiate-naive spinal slices, suggesting that NMDA presynaptic receptors are capable of increasing glutamate release even in the opiate-naive slice. Regardless, we report here that, in contrast to the opiate-naive slice, NMDA induces an increase in mEPSC frequency in spinal slices from opiate-tolerant neonatal rats. The reason for this seeming change in presynaptic NMDAR function in response to previous opiate exposure is not evident. Studies are underway examining the role of possible mechanisms that might alter the physiological effects of NMDA application, including differential NMDA subunit expression (Yamakura and Shimoji, 1999; Gaunitz et al., 2002; Martin et al., 2004) and/or receptor phosphorylation (Mayer et al., 1995; MacDonald et al., 2001; Pan, 2003; Smith et al., 2003; Kalia et al., 2004).

Apart from changes in NMDA receptor function, our anatomical data clearly show that there is an increase in primary afferent NMDAR number in the spinal dorsal horn of opiatetolerant neonatal rats. These data support an increased synthesis and/or trafficking of NMDAR1 into SP terminals of morphinetreated rats as compared with controls. More of these terminals contain NMDA receptors, but individual terminals have comparable receptor densities and cytoplasm/membrane distribution ratios. Moreover, no such opiate-induced differences are seen in profiles postsynaptic to SP-containing primary afferents. In a previous study we found a higher incidence of NMDAR1 in dendritic targets of SP axon terminals in opiate-naive rats as well as an even lower incidence of presynaptic labeling for NMDAR1 in SP afferents (Aicher et al., 1997). Differences from the current data may be attributable to differences between the lumbar spinal cord studied here and the cervical spinal cord studied previously or may, instead, represent differences between the neonates studied here and adult rats studied previously.

It is well known that NMDA receptor number and function change significantly during development (Pattinson and Fitzgerald, 2004; Fitzgerald, 2005). Zhu and Barr (2003) previously have investigated the ontogeny of NMDAR-dependent opiate tolerance. They found that, although opiate analgesic tolerance in 1 -week-old rats was not inhibited by NMDAR blockade (MK801 ) at 2 and 3 weeks of age, NMDAR antagonists significantly attenuated tolerance induction. Zhu and Barr did not report the effects of NMDAR antagonists on tolerance expression in animals of any age. Our behavioral studies in 2- to 3-week-old rats confirm their findings that, like in the adult, NMDAR mechanisms play an important role in mediating opiate tolerance in this age group. Our electrophysiology and anatomy studies suggest a cellular mechanism for these effects.

\section{References}

Aicher SA, Reis DJ, Nicolae R, Milner TA (1995) Monosynaptic projections from the medullary gigantocellular reticular formation to sympathetic 
preganglionic neurons in the thoracic spinal cord. J Comp Neurol 363:563-580.

Aicher SA, Sharma S, Cheng PY, Pickel VM (1997) The N-methyl-Daspartate (NMDA) receptor is postsynaptic to substance P-containing axon terminals in the rat superficial dorsal horn. Brain Res 772:71-81.

Aicher SA, Sharma S, Pickel VM (1999) N-methyl-D-aspartate receptors are present in vagal afferents and their dendritic targets in the nucleus tractus solitarius. Neuroscience 91:119-132.

Allen RM, Dykstra LA (1999) The competitive NMDA receptor antagonist LY235959 modulates the progression of morphine tolerance in rats. Psychopharmacology (Berl) 142:209-214.

Arvanov VL, Seebach BS, Mendell LM (2000) NT-3 evokes an LTP-like facilitation of AMPA/kainate receptor-mediated synaptic transmission in the neonatal rat spinal cord. J Neurophysiol 84:752-758.

Bardoni R, Torsney C, Tong CK, Prandini M, MacDermott AB (2004) Presynaptic NMDA receptors modulate glutamate release from primary sensory neurons in rat spinal cord dorsal horn. J Neurosci 24:2774-2781.

Belozertseva IV, Dravolina OA, Neznanova ON, Danysz W, Bespalov AY (2000) Antinociceptive activity of combination of morphine and NMDA receptor antagonists depends on the inter-injection interval. Eur J Pharmacol 396:77-83.

Berger AJ, Takahashi T (1990) Serotonin enhances a low-voltage-activated calcium current in rat spinal motoneurons. J Neurosci 10:1922-1928.

Bie B, Pan ZZ (2005) Increased glutamate synaptic transmission in the nucleus raphe magnus neurons from morphine-tolerant rats. Mol Pain 1:7.

Bohn LM, Gainetdinov RR, Lin FT, Lefkowitz RJ, Caron MG (2000) Muopioid receptor desensitization by beta-arrestin- 2 determines morphine tolerance but not dependence. Nature 408:720-723

Carlezon Jr WA, Kosten TA, Nestler EJ (2000) Behavioral interactions caused by combined administration of morphine and MK-801 in rats. Psychopharmacology (Berl) 151:261-272.

Coderre TJ, Katz J, Vaccarino AL, Melzack R (1993) Contribution of central neuroplasticity to pathological pain: review of clinical and experimental evidence [comments]. Pain 52:259-285.

Coggeshall RE, Chung K, Chung JM, Langford LA (1981) Primary afferent axons in the tract of Lissauer in the monkey. J Comp Neurol 196:431-442.

Ding Y, Cesare P, Drew L, Nikitaki D, Wood JN (2000) ATP, P2X receptors and pain pathways. J Auton Nerv Syst 81:289-294.

Dobkin BH (1993) Neuroplasticity. Key to recovery after central nervous system injury [comments]. West J Med 159:56-60.

Duguid I, Sjostrom PJ (2006) Novel presynaptic mechanisms for coincidence detection in synaptic plasticity. Curr Opin Neurobiol 16:312-322.

Duguid IC, Smart TG (2004) Retrograde activation of presynaptic NMDA receptors enhances GABA release at cerebellar interneuron-Purkinje cell synapses. Nat Neurosci 7:525-533.

Eastman CL, Cheong Y-P, Terman GW (2001) Morphine tolerance in vivo inhibits $\mu$-opioid modulation of neurotransmission in the spinal slice. Soc Neurosci Abstr 27:616.11.

Elliott K, Hynansky A, Inturrisi CE (1994) Dextromethorphan attenuates and reverses analgesic tolerance to morphine. Pain 59:361-368.

Ferguson SS, Barak LS, Zhang J, Caron MG (1996) G-protein-coupled receptor regulation: role of G-protein-coupled receptor kinases and arrestins. Can J Physiol Pharmacol 74:1095-1110.

Fitzgerald M (2005) The development of nociceptive circuits. Nat Rev Neurosci 6:507-520.

Garcia-Junco-Clemente P, Linares-Clemente P, Fernandez-Chacon R (2005) Active zones for presynaptic plasticity in the brain. Mol Psychiatry 10:185-200.

Garraway SM, Petruska JC, Mendell LM (2003) BDNF sensitizes the response of lamina II neurons to high threshold primary afferent inputs. Eur J Neurosci 18:2467-2476.

Gaunitz C, Schuttler A, Gillen C, Allgaier C (2002) Formalin-induced changes of NMDA receptor subunit expression in the spinal cord of the rat. Amino Acids 23:177-182.

Gutstein HB, Trujillo KA (1993) MK-801 inhibits the development of morphine tolerance at spinal sites. Brain Res 626:332-334.

Harrison LM, Kastin AJ, Zadina JE (1998) Opiate tolerance and dependence: receptors, G-proteins, and antiopiates. Peptides 19:1603-1630.

Hawkins RD, Kandel ER, Siegelbaum SA (1993) Learning to modulate transmitter release: themes and variations in synaptic plasticity. Annu Rev Neurosci 16:625-665.

Hoffmann O, Wiesenfeld-Hallin Z (1996) Dextromethorphan potentiates morphine antinociception, but does not reverse tolerance in rats. NeuroReport 7:838-840.

Hsu MM, Wong CS (2000) The roles of pain facilitatory systems in opioid tolerance. Acta Anaesthesiol Sin 38:155-166.

Huang H, Bordey A (2004) Glial glutamate transporters limit spillover activation of presynaptic NMDA receptors and influence synaptic inhibition of Purkinje neurons. J Neurosci 24:5659-5669.

Kalia LV, Gingrich JR, Salter MW (2004) Src in synaptic transmission and plasticity. Oncogene 23:8007-8016.

Kovoor A, Nappey V, Kieffer BL, Chavkin C (1997) $\mu$ and $\delta$ opioid receptors are differentially desensitized by the coexpression of $\beta$-adrenergic receptor kinase 2 and $\beta$-arrestin 2 in Xenopus oocytes. J Biol Chem 272:27605-27611.

Kozela E, Popik P (2002) The effects of NMDA receptor antagonists on acute morphine antinociception in mice. Amino Acids 23:163-168.

Lao LJ, Song B, Marvizon JC (2003) Neurokinin release produced by capsaicin acting on the central terminals and axons of primary afferents: relationship with $\mathrm{N}$-methyl-D-aspartate and $\mathrm{GABA}_{\mathrm{B}}$ receptors. Neuroscience 121:667-680.

Laulin JP, Celerier E, Larcher A, Le Moal M, Simonnet G (1999) Opiate tolerance to daily heroin administration: an apparent phenomenon associated with enhanced pain sensitivity. Neuroscience 89:631-636.

Li P, Zhuo M (1998) Silent glutamatergic synapses and nociception in mammalian spinal cord. Nature 393:695-698.

Li P, Wilding TJ, Kim SJ, Calejesan AA, Huettner JE, Zhuo M (1999) Kainate-receptor-mediated sensory synaptic transmission in mammalian spinal cord. Nature 397:161-164.

Lien CC, Mu Y, Vargas-Caballero M, Poo MM (2006) Visual stimuliinduced LTD of GABAergic synapses mediated by presynaptic NMDA receptors. Nat Neurosci 9:372-380.

Liu H, Mantyh PW, Basbaum AI (1997) NMDA-receptor regulation of substance P release from primary afferent nociceptors. Nature 386:721-724.

Liu JG, Anand KJ (2001) Protein kinases modulate the cellular adaptations associated with opioid tolerance and dependence. Brain Res Brain Res Rev 38:1-19.

Loftis JM, Janowsky A (2003) The N-methyl-D-aspartate receptor subunit NR2B: localization, functional properties, regulation, and clinical implications. Pharmacol Ther 97:55-85.

Lopes da Silva FH, Kamphuis W, Wadman WJ (1992) Epileptogenesis as a plastic phenomenon of the brain, a short review. Acta Neurol Scand Suppl 140:34-40.

Lowe JD, Celver JP, Gurevich VV, Chavkin C (2002) $\mu$-Opioid receptors desensitize less rapidly than $\delta$-opioid receptors due to less efficient activation of arrestin. J Biol Chem 277:15729-15735.

MacDonald JF, Kotecha SA, Lu WY, Jackson MF (2001) Convergence of PKC-dependent kinase signal cascades on NMDA receptors. Curr Drug Targets 2:299-312.

Manning BH, Mao J, Frenk H, Price DD, Mayer DJ (1996) Continuous co-administration of dextromethorphan or MK-801 with morphine: attenuation of morphine dependence and naloxone-reversible attenuation of morphine tolerance. Pain 67:79-88.

Mao J, Price DD, Mayer DJ, Lu J, Hayes RL (1992) Intrathecal MK-801 and local nerve anesthesia synergistically reduce nociceptive behaviors in rats with experimental peripheral mononeuropathy. Brain Res 576:254-262.

Mao J, Price DD, Mayer DJ (1995) Mechanisms of hyperalgesia and morphine tolerance: a current view of their possible interactions. Pain 62:259-274.

Martin G, Guadano-Ferraz A, Morte B, Ahmed S, Koob GF, De Lecea L, Siggins GR (2004) Chronic morphine treatment alters $N$-methyl-Daspartate receptors in freshly isolated neurons from nucleus accumbens. J Pharmacol Exp Ther 311:265-273.

Mayer DJ, Mao J, Price DD (1995) The association of neuropathic pain, morphine tolerance and dependence, and the translocation of protein kinase C. NIDA Res Monogr 147:269-298.

McNally GP, Westbrook RF (1998) Effects of systemic, intracerebral, or intrathecal administration of an $\mathrm{N}$-methyl-D-aspartate receptor antagonis on associative morphine analgesic tolerance and hyperalgesia in rats. Behav Neurosci 112:966-978.

Moore KA, Kohno T, Karchewski LA, Scholz J, Baba H, Woolf CJ (2002) Partial peripheral nerve injury promotes a selective loss of GABAergic inhibition in the superficial dorsal horn of the spinal cord. J Neurosci 22:6724-6731. 
Pan ZZ (2003) Opioid tolerance in adult and neonatal rats. Methods Mol Med 84:223-232.

Pattinson D, Fitzgerald M (2004) The neurobiology of infant pain: development of excitatory and inhibitory neurotransmission in the spinal dorsal horn. Reg Anesth Pain Med 29:36-44.

Petrenko AB, Yamakura T, Baba H, Shimoji K (2003) The role of $N$-methylD-aspartate (NMDA) receptors in pain: a review. Anesth Analg 97:1108-1116.

Pittaluga A, Raiteri M (1990) Release-enhancing glycine-dependent presynaptic NMDA receptors exist on noradrenergic terminals of hippocampus. Eur J Pharmacol 191:231-234.

Popik P, Kozela E, Danysz W (2000) Clinically available NMDA receptor antagonists memantine and dextromethorphan reverse existing tolerance to the antinociceptive effects of morphine in mice. Naunyn Schmiedebergs Arch Pharmacol 361:425-432.

Proudfit HK, Hammond DL (1981) Alterations in nociceptive threshold and morphine-induced analgesia produced by intrathecally administered amine antagonists. Brain Res 218:393-399.

Redwine KE, Trujillo KA (2003) Effects of NMDA receptor antagonists on acute $\mu$-opioid analgesia in the rat. Pharmacol Biochem Behav 76:361-372.

Samson RD, Pare D (2005) Activity-dependent synaptic plasticity in the central nucleus of the amygdala. J Neurosci 25:1847-1855.

Shimoyama N, Shimoyama M, Inturrisi CE, Elliott KJ (1996) Ketamine attenuates and reverses morphine tolerance in rodents. Anesthesiology 85:1357-1366.

Smith FL, Javed RR, Elzey MJ, Dewey WL (2003) The expression of a high level of morphine antinociceptive tolerance in mice involves both PKC and PKA. Brain Res 985:78-88.

Suarez LM, Suarez F, Del Olmo N, Ruiz M, Gonzalez-Escalada JR, Solis JM (2005) Presynaptic NMDA autoreceptors facilitate axon excitability: a new molecular target for the anticonvulsant gabapentin. Eur J Neurosci 21:197-209.

Terman GW, Eastman CL, Chavkin C (2001) Mu opiates inhibit long-term potentiation induction in the spinal cord slice. J Neurophysiol 85:485-494.

Terman GW, Jin W, Cheong YP, Lowe J, Caron MG, Lefkowitz RJ, Chavkin C (2004) G-protein receptor kinase 3 (GRK3) influences opioid analgesic tolerance but not opioid withdrawal. Br J Pharmacol 141:55-64.
Thomson LM, Zeng J, Terman GW (2006) Differential effect of glutamate transporter inhibition on EPSCs in the morphine naive and morphine tolerant neonatal spinal cord slice. Neurosci Lett 407:64-69.

Thomson LM, Zeng J, Terman GW (2006) An N-methyl-D-aspartate receptor-mediated large, low-frequency, spontaneous excitatory postsynaptic current in neonatal rat spinal dorsal horn neurons. Neuroscience 141:1489-1501.

Tiseo PJ, Inturrisi CE (1993) Attenuation and reversal of morphine tolerance by the competitive $N$-methyl-D-aspartate receptor antagonist, LY274614. J Pharmacol Exp Ther 264:1090-1096.

Trujillo KA, Akil H (1991) Inhibition of morphine tolerance and dependence by the NMDA receptor antagonist MK-801. Science 251:85-87.

Trujillo KA, Akil H (1994) Inhibition of opiate tolerance by noncompetitive $N$-methyl-D-aspartate receptor antagonists. Brain Res 633:178-188.

Tzingounis AV, Nicoll RA (2004) Presynaptic NMDA receptors get into the act. Nat Neurosci 7:419-420.

Vanderah TW, Suenaga NM, Ossipov MH, Malan Jr TP, Lai J, Porreca F (2001) Tonic descending facilitation from the rostral ventromedial medulla mediates opioid-induced abnormal pain and antinociceptive tolerance. J Neurosci 21:279-286.

Willcockson WS, Chung JM, Hori Y, Lee KH, Willis WD (1984) Effects of iontophoretically released peptides on primate spinothalamic tract cells. J Neurosci 4:741-750.

Woolf CJ (1981) Intrathecal high dose morphine produces hyperalgesia in the rat. Brain Res 209:491-495.

Yamakura T, Shimoji K (1999) Subunit- and site-specific pharmacology of the NMDA receptor channel. Prog Neurobiol 59:279-298.

Yang J, Woodhall GL, Jones RS (2006) Tonic facilitation of glutamate release by presynaptic NR2B-containing NMDA receptors is increased in the entorhinal cortex of chronically epileptic rats. J Neurosci 26:406-410.

Yu Y, Zhang L, Yin X, Sun H, Uhl GR, Wang JB (1997) $\mu$-Opioid receptor phosphorylation, desensitization, and ligand efficacy. J Biol Chem 272:28869-28874.

Zhu H, Barr GA (2003) Ontogeny of NMDA receptor-mediated morphine tolerance in the postnatal rat. Pain 104:437-447. 